\title{
A New Way of Representing Diagnostic Keys
}

\author{
By R. W. PA Y NE \\ Rothamsted Experimental Station, Harpenden, Hertfordshire \\ E. W A LTON \\ Young's Manor, Chilham, Canterbury, Kent \\ AND J. A. BARNETT \\ School of Biological Sciences, University of East Anglia, Norwich \\ (Received 13 February 1974)
}

We propose a new way of representing identification keys that has certain advantages over traditional forms. The new lay-out is mainly intended for binary keys and, in particular, long keys, such as that for the yeasts of Barnett \& Pankhurst (1974). We are not aware that this form of key has been described elsewhere (cf. Voss, I952). Two conventional forms of key are shown in Fig. I $(a, b)$ and the new form in Fig. I $(c)$. The same part of the yeast key (Barnett \& Pankhurst, 1974) is used in each case.

Each line of the new form constitutes a complete question with its answers, negative to the left, positive to the right. This gives the following advantages. First, it is quicker to use. The eye travels straight from the test name to the appropriate answer and in the same direction for each kind of answer (positive or negative). Secondly, since each test name or description is given only once, the new form takes up about half the space of the conventional forms.

Fig. I $(d)$ shows a possible generalization of the new form for use when tests have more than two levels of response or when levels for different tests have different descriptions. This arrangement is less elegant than that shown in Fig. I (c) and the first advantage is no longer fully applicable; but when tests with more than two levels are included, even more space is saved over the conventional forms.

No new program is necessary for constructing our form of key by computer, merely a new sub-routine for printing. This sub-routine has much the same number of instructions as that used for the old forms, and computer time is saved as there is less than half the length of print-out.

We thank Mr J. S. L. Gilmour and Dr S. M. Walters for their comments.

\section{REFERENCES}

Barnett, J. A. \& Pankhurst, R. J. (1974). A New Key to The Yeasts. Amsterdam: North-Holland Publishing.

Voss, E. G. (1952). The history of keys and phylogenetic trees in systematic biology. Journal of the Scientific Laboratories of Denison University 43, $\mathbf{1 - 2 5}$. 

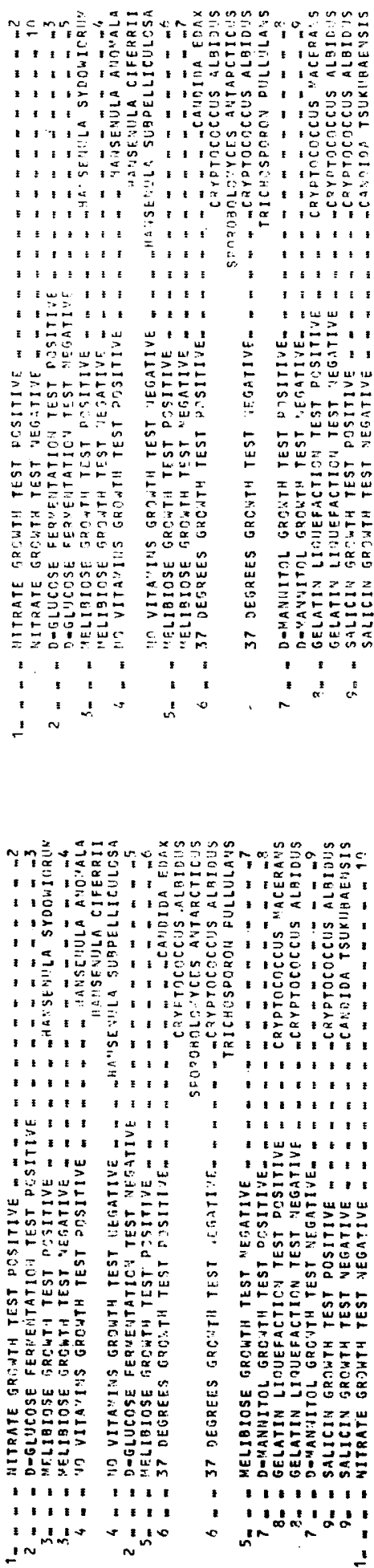
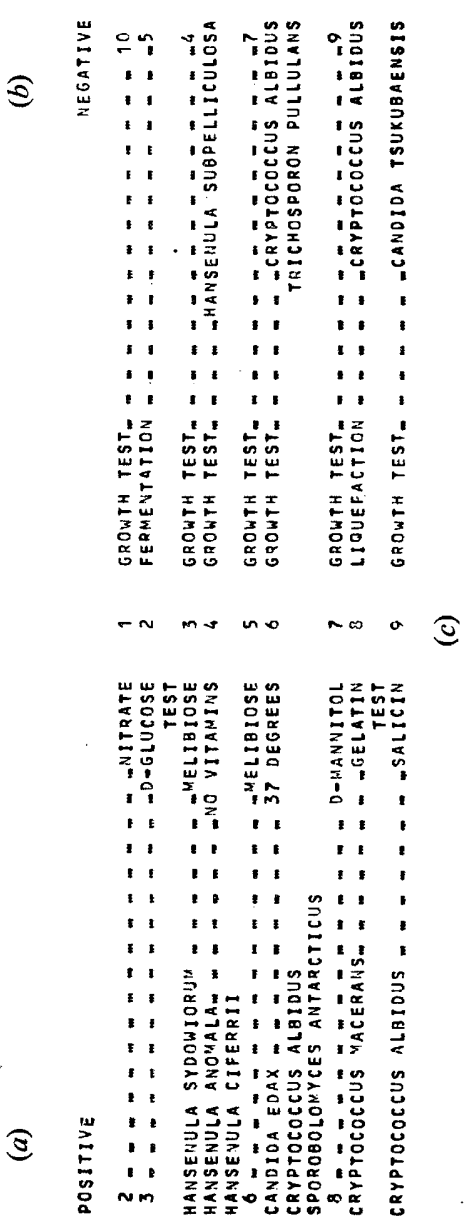

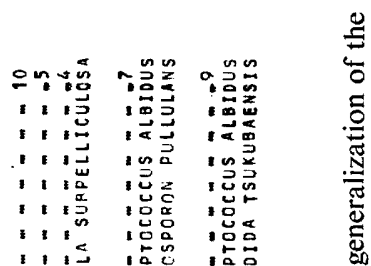

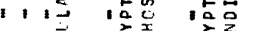

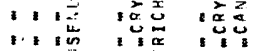

112 1:

1.1.1:1:18

1,11

岂岂岂 岩

$\because B$

岂岂

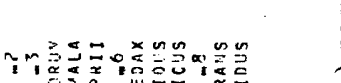

1. 1.

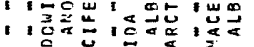

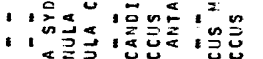

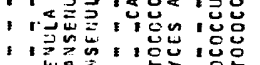

1
1
1
1
1
1

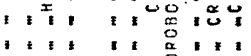

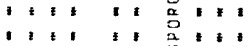

$1: 1:$ :

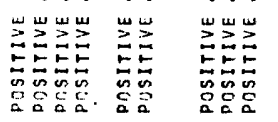

8

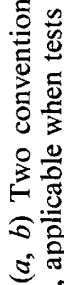

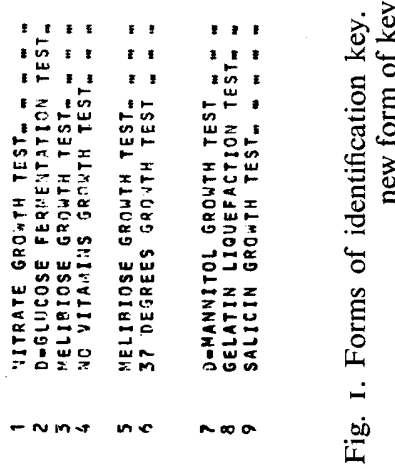

